\title{
Routine metabolism of Antarctic krill (Euphausia superba) in South Georgia waters: absence of metabolic compensation at its range edge
}

\author{
Geraint A. Tarling ${ }^{1}$ (D) \\ Received: 14 October 2019 / Accepted: 25 May 2020 / Published online: 4 July 2020 \\ (c) The Author(s) 2020
}

\begin{abstract}
Routine respiration rates in the South Georgia stock of Antarctic krill (Euphausia superba) were measured to compare with previously published measurements on stocks from colder locations further south. Within the natural temperature range of this species $\left(-1.8^{\circ}\right.$ to $\left.5.5^{\circ} \mathrm{C}\right)$, respiration rate data from both the present and previous studies were adequately fitted by a single Arrhenius regression ( $Q_{10}$ of 2.8), although South Georgia krill showed an upward deviation from this regression between $0^{\circ}$ and $2{ }^{\circ} \mathrm{C}$ (the lower temperature range at South Georgia). Metabolic compensation (i.e. the comparative lowering of respiration rate) at the high temperatures experienced at South Georgia was not apparent, although the higher than predicted metabolic rates at low temperatures suggests acclimation of South Georgia krill to a warm water lifestyle. Weight-specific respiration rate was significantly higher in sub-adults and adults compared to juveniles, highlighting the metabolic burden of reproduction. South Georgia krill showed no further increase in respiration rate when exposed to acute temperatures $\left(5.5-12.2{ }^{\circ} \mathrm{C}\right)$, indicating that they were already at the limit of aerobic capacity by $5.5^{\circ} \mathrm{C}$. Overall, this study shows that even small degrees of additional warming to South Georgia waters are likely to make conditions there metabolically unsustainable for Antarctic krill.
\end{abstract}

\section{Introduction}

Euphausiids represent an important component in marine food webs, linking primary production to higher predators (Mauchline 1980). Moreover, they are major contributors to world plankton community biomass, second only to copepods (Longhurst 1998; Ikeda 2013). In some regions of the Southern Ocean, euphausiids are the primary contributor to biomass, of which a large proportion are Antarctic krill (Euphausia superba). This species constitutes a crucial food source for many mammalian and avian predatory species

Responsible Editor: A. E. Todgham.

Reviewed by: K. Swadling and an undisclosed expert.

Electronic supplementary material The online version of this article (https://doi.org/10.1007/s00227-020-03714-w) contains supplementary material, which is available to authorized users.

Geraint A. Tarling

gant@bas.ac.uk

1 British Antarctic Survey, Natural Environment Research Council, High Cross, Madingley Rd, Cambridge CB3 OET, UK
(Everson 1984) and have been shown to be vital for breeding success (Croxall et al. 1988). Antarctic krill are additionally of interest to commercial fisheries (Everson and Goss 1991; Nicol et al. 2012), necessitating effective resource management that can account for temporal and spatial variability in krill biomass (Trathan et al. 2003).

The pelagic ecosystem at South Georgia is extremely productive, where intense phytoplankton blooms support a rich foodweb (Atkinson et al. 2001). Antarctic krill reaches notably high levels of biomass in this region and are consumed by large populations of krill-dependent predators (Veit et al. 1993; Croxall et al. 1999). South Georgia is at or near the northerly limit for this species (Cuzin-Roudy et al. 2014) and stocks found there are considered to be close to their physiological limits (Opalinski 1991; Flores et al. 2012). Sea-surface temperatures in South Georgia waters oscillate between 0 and $5.5^{\circ} \mathrm{C}$ over the course of the year (Whitehouse et al. 2008). These warmer temperatures are already beyond the upper lethal limit identified for Antarctic krill populations located further south (McWhinnie and Marciniak 1964; Aarset and Torres 1989), which suggests that there may be some physiological differences in Antarctic krill from different locations, especially with regards thermal responses. 
The issue of thermal response has been brought into greater focus given that the Antarctic Circumpolar Current has warmed more rapidly than the global ocean as a whole over recent decades, with mid-depth temperatures rising by $0.17^{\circ} \mathrm{C}$ between the 1950 s and the 1980 s (Gille 2002). South Georgia itself has experienced even more extreme warming, with one study reporting mean temperature in the top $100 \mathrm{~m}$ of the water column to have increased by $0.9^{\circ} \mathrm{C}$ in January and $2.3{ }^{\circ} \mathrm{C}$ in August over the past 80 years (Whitehouse et al. 2008). Predicting the future viability of Antarctic krill populations at South Georgia depends on parameterising how these organisms respond to warming. In this regard, physiological parameterisations carried out directly on South Georgia Antarctic krill are crucial.

One of the most fundamental physiological measurements is that of metabolic rate. In most instances, oxygen consumption rate, otherwise termed respiration rate, is used as a proxy for metabolic rate. In Antarctic krill, between 72 and $85 \%$ of assimilated carbon is respired (Ikeda 1984). Oxygen consumption is the sum of many different physiological processes occurring together, which include basal metabolism, swimming activity and the contribution from any feeding, growth, or gametogenesis in progress at the time of measurement (Clarke and Morris 1983). Measuring basal metabolism in euphausiids is difficult since individuals always maintain at least some level of motion (Swadling et al. 2005). Nevertheless, containment within measurement vessels constrains full levels of activity. Therefore, most studies on euphausiids report what has been termed "routine" metabolism, which represents basal metabolism plus an uncontrolled, but assumed to be minor, contribution from other processes, including low levels of swimming. With certain caveats,

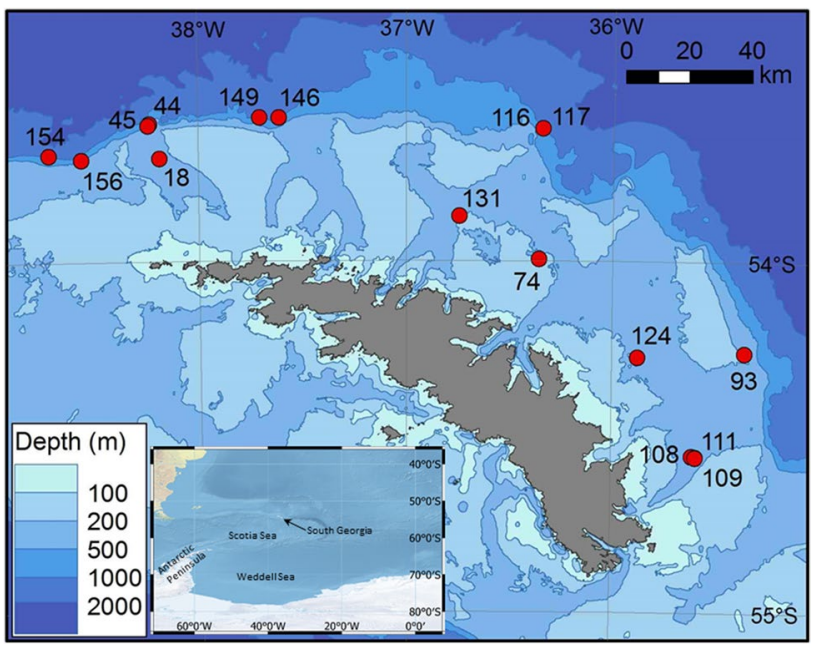

Fig. 1 Locations around South Georgia where there were successful net catches for Antarctic krill, subsequently used in respiration experiments. See Table 1 for further details the measurement of routine metabolism in euphausiids provides a comparative index of metabolic costs between populations, environments and species (Ikeda 2013; Tremblay et al. 2014).

Although limited to water masses poleward of the Polar Front, Antarctic krill still has a wide distributional range, comprising more than $20^{\circ}$ of latitude (Atkinson et al. 2008) and sea surface temperatures ranging from -1.8 to $5.5^{\circ} \mathrm{C}$ (Opalinski 1991). Northern krill (Meganyctiphanes norvegica) is arguably the nearest equivalent species in the northern hemisphere, both in terms of body size and distributional range, covering more than $40^{\circ}$ of latitude, and temperatures between 2 and $15^{\circ} \mathrm{C}$ (Tarling et al. 2010). Saborowski et al. (2002) measured in situ respiration rate in three distinct populations of this species, from the Mediterranean Sea, northern UK shelf and Kattegat Sea. Despite the contrasting temperatures, in situ respiration rates were similar between the three environments $(30-35 \mu \mathrm{mol}$ $\mathrm{O}_{2} \mathrm{mg}^{-1}$ dry $w \mathrm{w} \mathrm{h}^{-1}$ ). It was concluded that different populations of Northern krill compensated for differences in temperature to maintain a constant metabolic level.

Saborowski et al. (2002) also found that there was no metabolic compensation during short exposures of Northern krill to temperatures above or below those prevailing in their natural environment. Across the range of experimental temperatures, respiration rates followed an exponential curve, closely following van't Hoff's generalization. With no capacity for short term compensation, Saborowski et al. (2002) further surmised that similarity in in situ respiration rates of Northern krill between thermally contrasting environments was the result of long-term adaptations to local conditions.

For a species as widely distributed as Antarctic krill, compensating metabolic rate to counter contrasting thermal conditions has distinct advantages. The Southern Ocean is extremely seasonal and there is strong evidence that Antarctic krill alters its respiration rate beyond thermal expectations, with minimum rates in mid-winter and maximum rates in mid-summer (Meyer 2012; Tremblay et al. 2014). Increasing respiration rate in summer, particularly in colder higher latitude waters, may allow maximal use of the high productivity levels available, increasing development and maturation rates and allowing life-cycles to be completed (Thorpe et al. 2019). At lower latitudes, there is the opposite problem of metabolic costs potentially being in excess of consumption rates, so lowering respiration rate may allow an energy deficit to be avoided. Nevertheless, studies do not agree on whether Antarctic krill can compensate for temperature change in a similar way to Northern krill (Hirche 1984; Opalinski 1991). Furthermore, whether in situ respiration rates remain similar between Antarctic krill populations inhabiting thermally contrasting environments has yet to be fully considered because very few measurements have been made in comparatively warmer environments, such as South Georgia. 
Another aspect that requires further consideration is the potential differences in the relationship between temperature and metabolic rate between sexes and developmental stages. Adult male and female Antarctic krill exhibit marked dimorphism, with mature (gravid) females containing large distended ovaries filled with lipid rich oocytes. Clarke and Morris (1983) hypothesised that females have a higher energy intake than males to amass such resources. An alternative hypothesis is that females have a comparatively lower metabolism and so have a higher net energy gain per unit resource consumed. To date, comparisons of male and female Antarctic krill metabolic rate have not revealed any differences (Klekowski et al. 1991), although significant differences have been found between adults and juveniles (Klekowski and Opalinski 1989).

The present study measures routine metabolism of different sexes and developmental stages within the South Georgian population of Antarctic krill. Routine metabolism is measured across two temperature ranges, $0-5.5^{\circ} \mathrm{C}$, which represents the ambient range of temperatures that prevail in South Georgia surface waters over a seasonal cycle, and $5.5-12.5{ }^{\circ} \mathrm{C}$, representing extreme temperatures that, although unlikely to be encountered in the natural environment, can indicate physiological capacity (Pörtner 2002). Within these two temperature ranges, I investigate the influence of body size, sex and developmental stage on routine respiration rate. Comparisons are made with measurements of routine respiration rate made by other studies across a wide range of Southern Ocean locations.

\section{Materials and methods}

\section{Field sampling}

Antarctic krill were caught at a variety of locations in the vicinity of South Georgia on board the RRS James Clark Ross between 21st December 2010 and 19th January 2011 (Cruise JR245). They were captured with a $1 \mathrm{~m}^{2}$ MIK net fitted with a 2-mm mesh and non-filtering cod-end deployed obliquely to maximum depths of between 50 and $60 \mathrm{~m}$ (Table 1, Fig. 1). Where catches were successful, around 100 individuals were randomly extracted immediately and transferred to $50 \mathrm{~L}$ containers filled with ambient surface seawater, where they were left for a period of between 12 and $48 \mathrm{~h}$ before transfer to an incubation apparatus. The remainder of the catch was analysed for population structure through random extraction of around 200 individuals on which standard body length (TL) was measured following Morris et al. (1988), from the anterior edge of the eye to the tip of the telson and rounded down to nearest $\mathrm{mm}$. Sex and developmental stage were categorised according to Makarov and Denys (1980). Full depth temperature profiles were obtained at regular intervals throughout the field campaign with a calibrated SeaBird $911+$ CTD .

\section{Incubation apparatus}

The incubation apparatus (a Spartel Temperature Gradient Incubator) contained a hollow rectangular aluminium block $(1.3 \mathrm{~m} \times 0.5 \mathrm{~m})$ housed within an insulating outer-box, which maintained a temperature gradient across its long axis (Fig. 2). The gradient was achieved by circulating coolant within the block, cold coolant being fed in and out from one end (chilled and circulated by C-85D + FC-500 units) and warm coolant from the other (via a C-400 unit). An internal division half way along the block prevented direct mixing between the warm and cold coolants. A maximum of seventy-two $250 \mathrm{ml}$ glass stoppered bottles were placed on top of this block in advance of an incubation experiment for a period of time (usually $3 \mathrm{~h}$ ) sufficient to equilibrate their temperature to that of the specific block location. All bottles were filled with fine-filtered seawater (filtered through $0.2 \mu \mathrm{m}$ Sartorius membrane filters). The minimum withinbottle temperature was $0{ }^{\circ} \mathrm{C}$, and the maximum, $12.2{ }^{\circ} \mathrm{C}$. Between 5 and 8 bottles (median 6) were placed evenly along this gradient per respiration experiment, and a total of 24 experiments were carried out over the course of the study.

\section{Respiration experiments}

Krill were extracted from the 50-L containers and categorised as follows: (i) juvenile, (ii) small sub-adult, (iii) large sub-adult, (iv) adult female (v) adult male. It is to be noted that a large number of adult females were gravid, containing swollen ovaries and a purple discolouration to the cephalothorax. Numbers introduced to each bottle varied according to category: 10 per bottle for juveniles, 5 per bottle for small sub-adults, 3 per bottle for large sub-adults, and 1 per bottle for adult females and males. These numbers were arrived at through trials where the aim was to achieve a sufficient drop in $\mathrm{O}_{2}$ concentration within 90 min without overly affecting respiratory performance (Clarke and Morris 1983; Opalinski 1991).

Respiration rates were estimated by determining the concentration of $\mathrm{O}_{2}$ in the bottles at the start and end of an experiment. After introduction into the bottles, the krill were left to settle for around $10 \mathrm{~min}$. The temperature of the bottle was then taken and a stopper placed on the bottle, taking care not to trap any bubbles. The first $\mathrm{O}_{2}$ measurement was made immediately afterwards and a second after a period of between 60 and $90 \mathrm{~min}$.

$\mathrm{O}_{2}$ concentration was measured via factory-calibrated Presens oxygen sensor spots glued to the inside neck of the 250-ml stoppered bottles using silicone rubber compound. The spots were read by a fibre-optic probe held to 
Table 1 Euphausia superba: net catches from which Antarctic krill were extracted for respiration experiments

\begin{tabular}{|c|c|c|c|c|c|}
\hline Event No. & Lat $\left({ }^{\circ} \mathrm{S}\right)$ & Long $\left({ }^{\circ} \mathrm{W}\right)$ & Date & Time (GMT) & Max. net depth \\
\hline 18 & 53.70695 & 38.18605 & $25 / 12 / 2010$ & $\begin{array}{l}00: 37: 00 \\
00: 57: 49\end{array}$ & $21 \mathrm{~m}$ \\
\hline 44 & 53.60767 & 38.23436 & $28 / 12 / 2010$ & $\begin{array}{l}01: 24: 49 \\
01: 55: 52\end{array}$ & $58 \mathrm{~m}$ \\
\hline 45 & 53.61291 & 38.24039 & $28 / 12 / 2010$ & $\begin{array}{l}02: 45: 53 \\
03: 10: 41\end{array}$ & $44 \mathrm{~m}$ \\
\hline 74 & 53.99585 & 36.35807 & $01 / 01 / 2011$ & $\begin{array}{l}00: 19: 42 \\
00: 45: 36\end{array}$ & $59 \mathrm{~m}$ \\
\hline 93 & 54.26053 & 35.35364 & 03/01/2011 & $\begin{array}{l}22: 20: 30 \\
22: 36: 27\end{array}$ & $40 \mathrm{~m}$ \\
\hline 108 & 54.55503 & 35.60416 & $06 / 01 / 2011$ & $\begin{array}{l}16: 40: 00 \\
17: 03: 34\end{array}$ & Unknown \\
\hline 109 & 54.55829 & 35.58579 & 06/01/2011 & $\begin{array}{l}17: 32: 17 \\
18: 00: 32\end{array}$ & $47 \mathrm{~m}$ \\
\hline 111 & 54.55915 & 35.58569 & 07/01/2011 & $\begin{array}{l}01: 02: 48 \\
01: 16: 35\end{array}$ & Unknown \\
\hline 116 & 53.62301 & 36.34162 & 08/01/2011 & $\begin{array}{l}00: 47: 29 \\
01: 47: 53\end{array}$ & $55 \mathrm{~m}$ \\
\hline 117 & 53.62300 & 36.34105 & 08/01/2011 & $\begin{array}{l}02: 22: 23 \\
02: 52: 12\end{array}$ & $38 \mathrm{~m}$ \\
\hline 124 & 54.27473 & 35.87499 & 09/01/2011 & $\begin{array}{l}01: 47: 38 \\
02: 10: 04\end{array}$ & Unknown \\
\hline 131 & 53.87294 & 36.74385 & $10 / 01 / 2011$ & $\begin{array}{l}04: 43: 09 \\
05: 10: 45\end{array}$ & Unknown \\
\hline 146 & 53.59231 & 37.61264 & $13 / 01 / 2011$ & $\begin{array}{l}02: 14: 31 \\
02: 28: 58\end{array}$ & $36 \mathrm{~m}$ \\
\hline 149 & 53.59129 & 37.70458 & $13 / 01 / 2011$ & $\begin{array}{l}05: 23: 55 \\
05: 43: 15\end{array}$ & Unknown \\
\hline 154 & 53.69436 & 38.71951 & $14 / 01 / 2011$ & $\begin{array}{l}01: 53: 29 \\
02: 19: 20\end{array}$ & $49 \mathrm{~m}$ \\
\hline 156 & 53.70875 & 38.56402 & $14 / 01 / 2011$ & $\begin{array}{l}04: 27: 21 \\
04: 54: 03\end{array}$ & $50 \mathrm{~m}$ \\
\hline
\end{tabular}

Note that for nets where sensor failures meant that maximum net depth was "unknown", maximum depth was most likely within the range of other nets for which such information was collected successfully (i.e. between 21 and $59 \mathrm{~m}$ ). Local time was GMT-3 h

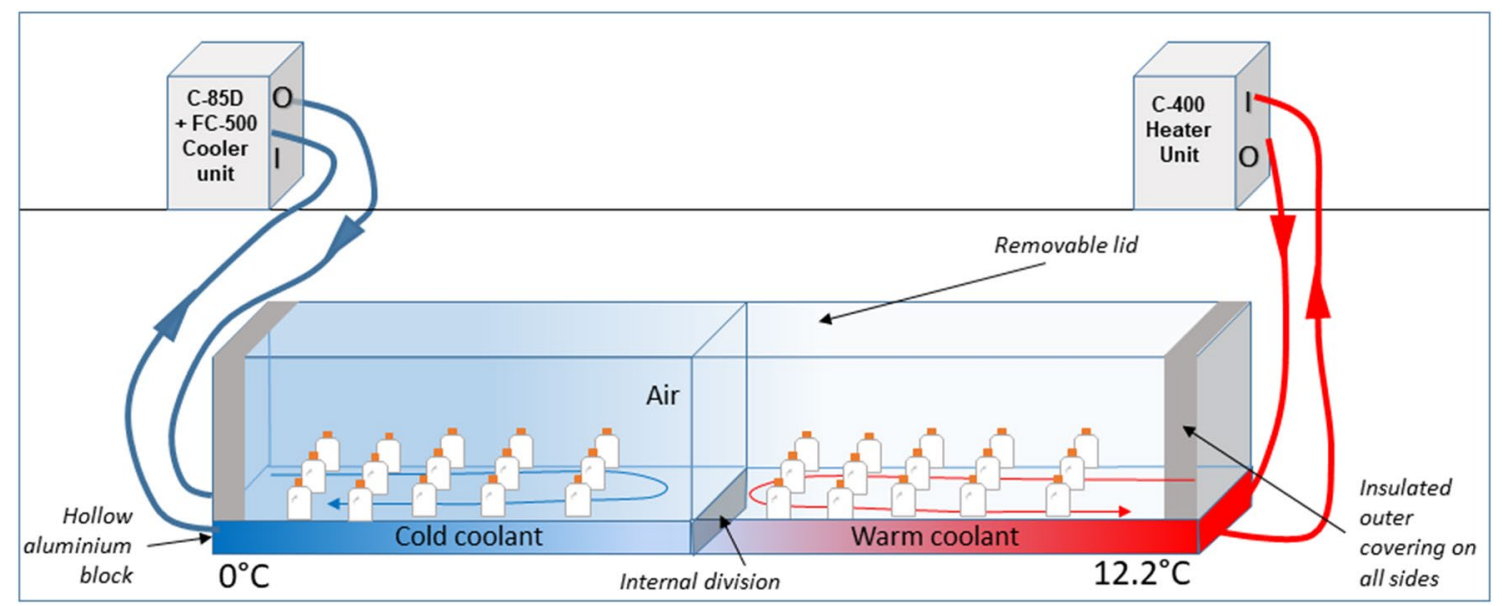

Fig. 2 Schematic showing the setup of the incubation apparatus (not to scale). $I$ In; $O$ Out. See text for further details 
the outside wall of the glass, at a sample rate of 1 reading per second. Readings were taken over a period of approximately $1 \mathrm{~min}$ in units of $\mu \mathrm{mol} \mathrm{L}{ }^{-1}$ (precision of three decimal places), from which an average was derived, excluding any outlier measurements.

After the second measurement was made, the krill were extracted from the bottles and their TL measured as above. Individuals were subsequently dissected for a variety of further analyses not considered here.

\section{Biometric conversions}

Individual dry weight was estimated using TL to dry weight regressions provided by Atkinson et al. (2006). These were considered suitable given: (i) they were obtained from krill caught in the same geographic region and at the same time of year as the present study and (ii) separate regressions were derived for different developmental stages and sexes similar to those discriminated in the present study. The respective regressions were as follows:

Juvenile:

$\log _{10} \mathrm{DW}=4.09 \log _{10} \mathrm{TL}-4.51$

Sub-adult:

$\log _{10} \mathrm{DW}=3.67 \log _{10} \mathrm{TL}-3.83$

Adult female:

$\log _{10} \mathrm{DW}=53.74 \log _{10} \mathrm{TL}-3.90$

Adult male:

$\log _{10} \mathrm{DW}=3.60 \log _{10} \mathrm{TL}-3.76$,

where $D W$ is dry weight in $\mathrm{mg}$ and $T L$ is standard body length in $\mathrm{mm}$.

\section{Data compilation}

A compilation of previously published data $(C O M P)$ was carried out to relate to respiration rates measured by the present study (see Electronic Supplementary Material). The COMP dataset only included studies where direct measurements of oxygen consumption were made within a few days of capture at temperatures within the natural environmental range $\left(-1.8\right.$ to $\left.5.5{ }^{\circ} \mathrm{C}\right)$. Furthermore, COMP was limited to studies which carried out measurements on krill that were at least equivalent to the minimum individual body size encountered in the present study (i.e. $>0.01 \mathrm{~g} \mathrm{DW}$ ).

\section{Analytical procedures}

Data from the present study was divided into two sub-sets: (i) 0 to $5.5^{\circ} \mathrm{C}$, the natural seasonal temperature range at South Georgia (SG_ambient) and (ii) 5.5 to $12.2^{\circ} \mathrm{C}$, an extreme temperature range (SG_extreme). SG_ambient was combined with the $C O M P$ dataset to produce a dataset of all respiration measurements taken within the natural environmental range of krill, referred to henceforth as $A M B I$ ENT (see Electronic Supplementary Material).

The scaling equation relating respiration rate per individual $\left(R_{\text {ind }}\right)$ to body mass in terms of dry weight $(D W$, $\mathrm{mg})$ is as follows:

$R=a \mathrm{DW}^{b}$,

where $a$ is a constant and $b$, the scaling exponent (SchmidtNielsen and Knut 1984). $b$ was estimated by fitting a 2-parameter power function to the AMBIENT dataset using curve fitting software (Sigmaplot 13.0.0.83, Systat Software, Inc). $b$ was used to account for body-size effects when deriving a weight-specific function for respiration rate $\left(R_{\mathrm{DW}}\right)$ in units of $\mu \mathrm{l} \mathrm{O}_{2} \mathrm{gDW}^{-\mathrm{b}} \mathrm{h}^{-1}$, following Ikeda (2013).

A number of different functional forms were fitted to identify one that best described the relationship between weight-specific respiration rate $\left(R_{\mathrm{DW}}\right)$ and temperature for both the AMBIENT and $S G \_$extreme datasets, including linear, log-linear, $\log -\log$ and the Arrhenius function, with the selected regression model having (i) a slope significantly different from 0 and (ii) the highest $R^{2}$ value. All fitting procedures were performed in Sigmaplot (13.0.0.83, Systat Software, Inc.).

The selected regression model was used to determine $Q_{10}$ for the $A M B I E N T$ dataset through estimating $R_{\mathrm{DW}}$ at the lowermost (T_lower) and uppermost (T_upper) temperatures within the dataset $\left[R_{\mathrm{DW}\left(\mathrm{T}_{-} \text {lower) }\right.}, R_{\mathrm{DW} \text { (T_upper) }}\right.$ respectively] and then applying van't Hoff's generalization as follows:

$Q_{10}=\left(\frac{R_{\mathrm{DW}\left(\mathrm{T} \_ \text {upper }\right)}}{R_{\mathrm{DW}\left(\mathrm{T} \_ \text {lower }\right)}}\right)^{10 /\left(\mathrm{T} \_ \text {upper-T_lower }\right)}$

It was not possible to calculate $Q_{10}$ for the $S G \_$extreme dataset, because the slopes of all fitted regression models were not significantly different from 0 .

Residuals $\left.\widehat{Y}_{i}-Y_{i}\right)$ from the selected regression model fitted to the AMBIENT dataset were explored further to identify any significant deviations. This involved separate analyses on the residuals from the two datasets concatenated within $A M B I E N T$, namely SG_ambient and COMP. The relationship between the residuals and temperature was explored by considering the fit of a number of functions, including linear, quadratic, $\log -\log$ and 
Arrhenius functions. In a further analysis, the residuals from $S G_{\text {a ambient }}$ were sub-divided according to sex and developmental stage and differences in residuals between these sub-divisions were tested using non-parametric Kruskal-Wallis One Way Analysis of Variance on Ranks, having failed tests for normality and equal variance. To isolate the group or groups differing significantly from each other, an all pairwise multiple comparison procedure (Dunn's method) was performed.

\section{Results}

\section{Prevailing environmental conditions}

Temperature in the upper mixed layer $(0-50 \mathrm{~m})$ varied between 3 and $3.8{ }^{\circ} \mathrm{C}$ across different cruise locations (Fig. 3). In the winter water layer, between 100 and $200 \mathrm{~m}$, temperature dropped to a minimum of around $0.7^{\circ} \mathrm{C}$. However, it subsequently increased with increasing depth, reaching just above $2{ }^{\circ} \mathrm{C}$ in the deeper layers $(>200 \mathrm{~m})$

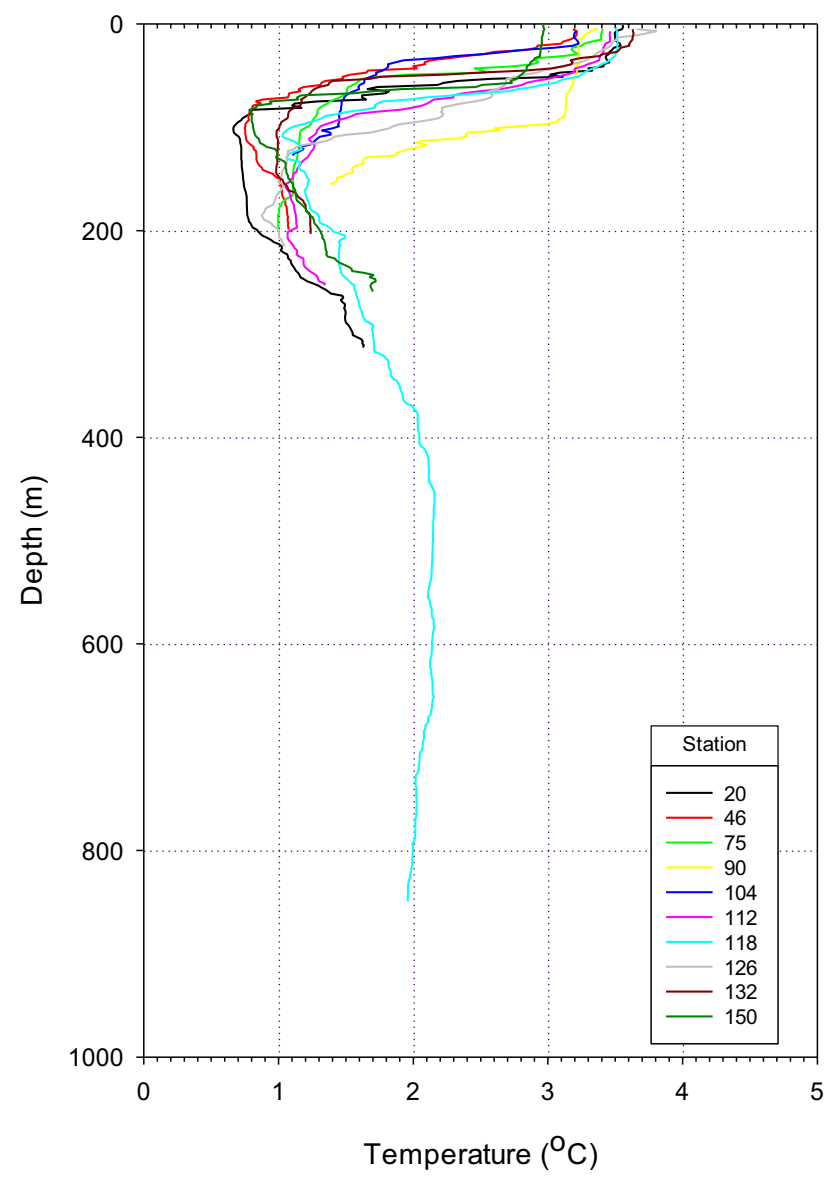

Fig. 3 Full-depth temperature profiles for each of the stations where net catches for Antarctic kill (Euphausia superba) were successful in offshore stations, principally through the influence of Circumpolar Deep Water (Thorpe et al. 2002).

\section{Population structure in South Georgia at time of capture}

The population at South Georgia consisted of a range of developmental stages, from juveniles of mean minimum size of $25 \mathrm{~mm}$ TL to adults reaching $60 \mathrm{~mm}$ TL (Fig. 4). The modal peak of the population was at $40 \mathrm{~mm}$. The population was dominated by sub-adults, which comprised $66 \%$ of the population, followed by juveniles (19\%) and then adults $(15 \%)$. The adult male to adult female ratio was $1: 1.8$, with females having a broader size range than males, but both sexes being evident in the uppermost body lengths.

\section{Scaling of respiration rate to body weight}

The fit of the scaling equation (Eq. 5) to data for individual respiration rate and body dry weight in the AMBIENT dataset was as follows:

$R_{\text {ind }}=616.2062 \mathrm{DW}^{0.9606} \quad R^{2}=0.75, F_{2,182}=828.22, P<0.001$,

where $R_{\text {ind }}$ is individual respiration rate in $\mu \mathrm{O}_{2}$ ind $^{-1} \mathrm{~h}^{-1}$, DW is dry weight in mg (Fig. 5).

The exponent of 0.9606 indicated a relatively strong effect of body size on respiration rate, relative to the standard value of 0.75 (Ikeda 2013).

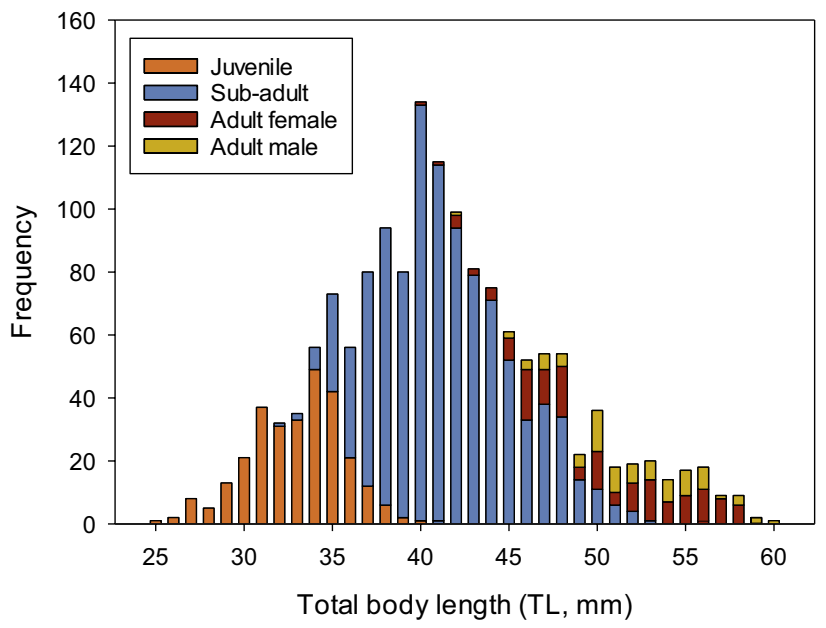

Fig. 4 Euphausia superba: frequency of standard body-lengths (following Morris et al. 1988) summed across all net catches during cruise JR304. Sex and developmental stage were classified according to Makarov and Denys (1980) 


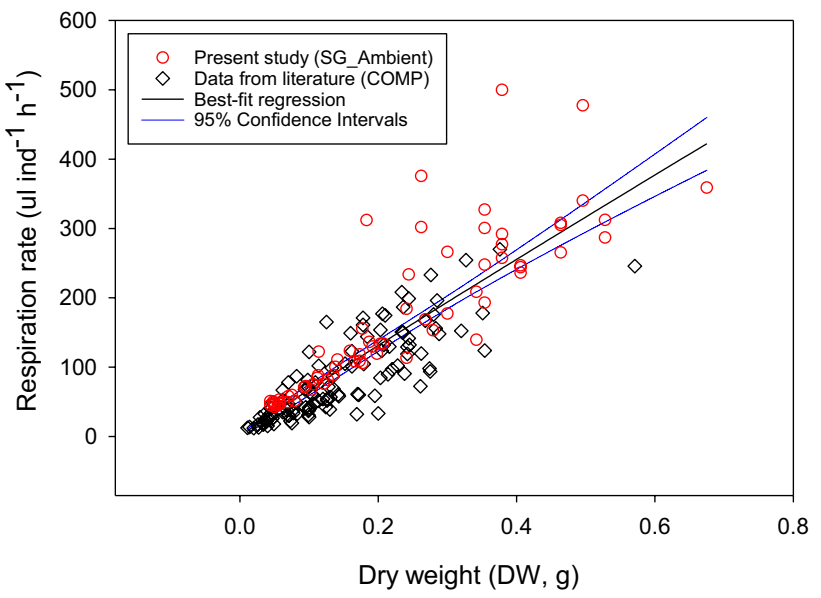

Fig. 5 Euphausia superba: Individual respiration rate $\left(R_{\text {ind }}, \mu 1\right.$ ind $\left.^{-1} \mathrm{~h}^{-1}\right)$ as a function of dry weight $(D W, \mathrm{~g})$ fitted by the scaling equation $R=a \mathrm{DW}^{b}$, where $a$ is $616.2062, b$ is $0.9606 . R^{2}$ was 0.7454

\section{Relationship between respiration rate and temperature within the ambient range}

The relationship between $R_{\mathrm{DW}}$ and temperature in the AMBIENT dataset was examined in both linear and log domains, including the Arrhenius function (Fig. 6). All fitted regressions indicated a significant relationship, with $R_{\mathrm{DW}}$ increasing with increasing temperature. The highest $R^{2}$ was achieved by the Arrhenius function (termed henceforth as the 'ambient Arrhenius regression') and was as follows: with variance being evenly distributed above and below 0 across the ambient temperature range (Fig. 7). However, in the $S G$ ambient dataset, there was an increasing trend of negative residuals (i.e. higher than expected individual values) towards lower temperatures. The pattern was best described by the following quadratic function:

$$
\begin{aligned}
\text { Resid } & =-1727.86+956.39 \frac{1000}{K}-132.34\left(\frac{1000}{K}\right)^{2} \\
R^{2} & =0.14, F_{3,66}=5.88, P=0.013,
\end{aligned}
$$

where Resid is residuals from Eq. 8 in units of LN $\left(\mu \mathrm{IO}_{2} \mathrm{gDW}^{-0.9606} \mathrm{~h}^{-1}\right)$.

Hence, although the $S G \_a m b i e n t$ data showed a reasonable fit to the ambient Arrhenius regression, described by Eq. 8 in the upper part of the ambient range $\left(>3{ }^{\circ} \mathrm{C}\right)$, there was an increasing deviation from this regression towards the lower temperatures $\left(0-2{ }^{\circ} \mathrm{C}\right)$, with $R_{\mathrm{DW}}$ being higher than otherwise expected at those temperatures.

Some significant differences were apparent in the distribution of residuals between sexes and developmental stages in the $S G_{-}$ambient dataset (Kruskal-Wallis 1-way ANOVA on ranks, $H_{3}=12.20, P=0.007$, Fig. 8). In the all pairwise multiple comparison test, residuals for juveniles were significantly different to both adult females and sub-adults, while there were no significant differences between adult males, adult females or subadults. The juvenile median was the only one of the four categories to be negative, although males did show a wide variation in residuals spanning both

$\mathrm{LN}\left(R_{\mathrm{DW}}\right)=34.3872-\left(7.6983 \cdot \frac{1000}{K}\right) \quad R^{2}=0.32, F_{2,183}=40241.35, P<0.001$,

where $R_{\mathrm{DW}}$ is weight-specific respiration rate in terms of dry weight $\left(\mu \mathrm{lO} \mathrm{g}_{\mathrm{DW}}{ }^{-0.9606} \mathrm{~h}^{-1}\right)$, and $\mathrm{K}$ is temperature (Kelvin).

Figure 6 highlights the paucity of measurements towards the upper ambient temperature range of Antarctic krill in previous studies (i.e. the COMP dataset), although the few studies that made measurements at temperatures above $3{ }^{\circ} \mathrm{C}$ generally fell within the range of values obtained by the present study at South Georgia ( $S G \_a m b i$ ent). The ambient Arrhenius regression had a $Q_{10}$ of 2.8 . Accordingly, this equates to around a doubling in $R_{\mathrm{DW}}$ between the upper and lower temperatures within the natural environmental range $\left(-1.8^{\circ} \mathrm{C}\right.$ and $5.5^{\circ} \mathrm{C}$ respectively). The regression explained $32 \%$ of the variance, reflecting the numerous data points that lay outside the $95 \%$ confidence bands.

When considering the residuals from the ambient Arrhenius regression, it is apparent that there is no further relationship with temperature within the COMP dataset, the negative and positive domains. Hence, overall, juvenile respiration rate was lower than that predicted by the ambient Arrhenius regression (Eq. 8) while respiration rate rose abruptly in sub-adult and adults to lie above this regression.

\section{Acute exposure to extreme temperatures}

When exposed to a range of extreme temperatures $\left(5.5-12.5^{\circ} \mathrm{C}\right)$, there was no further significant increase in $R_{\mathrm{DW}}$ with temperature (Fig. 9). $R_{\mathrm{DW}}$ ranged between 483.63 and $1730.32 \mu \mathrm{OO}_{2} \mathrm{gDW}^{-0.9606} \mathrm{~h}^{-1}$, with a mean of 923.08 $\mu \mathrm{O}_{2} \mathrm{mgDW}^{-0.9606} \mathrm{~h}^{-1}$. Assuming that $R_{\mathrm{DW}}$ is independent of temperature within this temperature range, there were significant differences between sexes and developmental stages, with females and sub-adults having a significantly lower $R_{\mathrm{DW}}$ compared to males and juveniles (Kruskal-Wallis 1-way ANOVA on Ranks, $H_{3}=28.468$, $P<0.001)$. The differences between the respective medians 

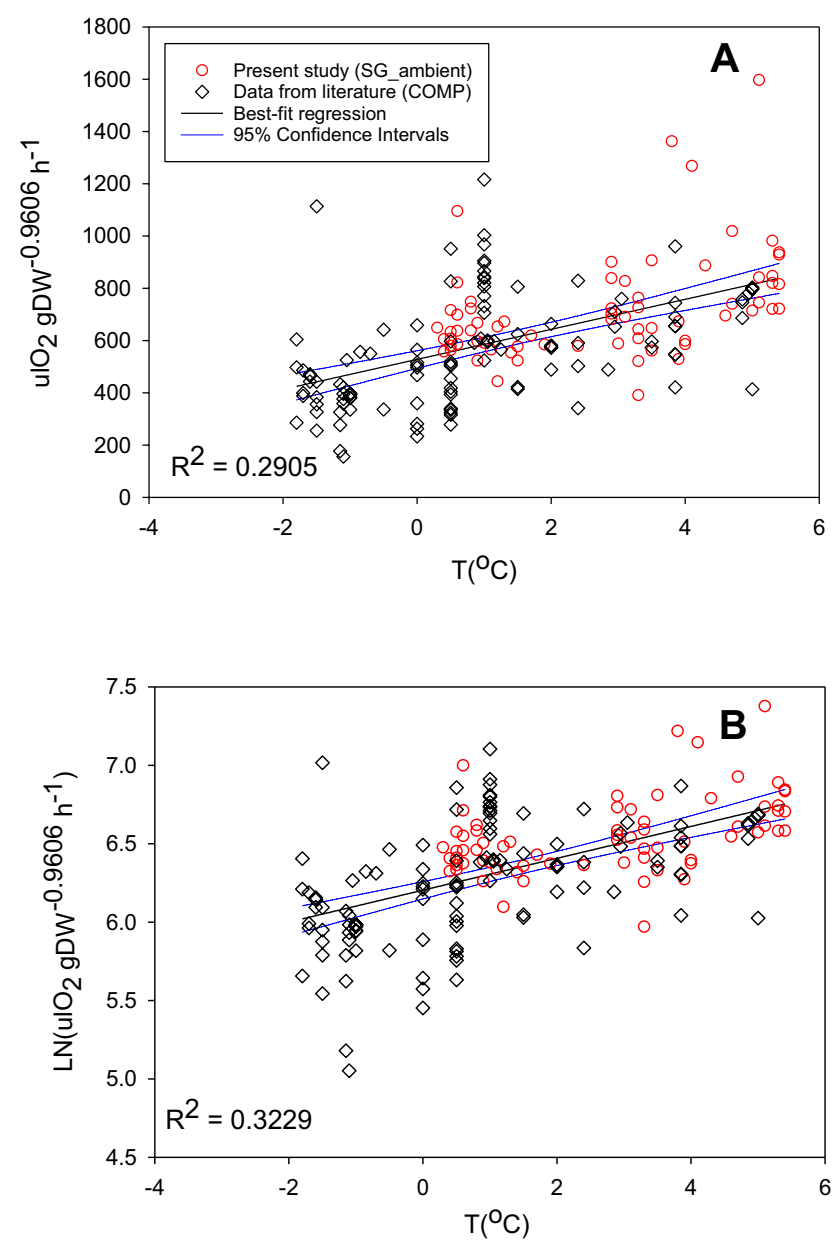

Fig. 6 Euphausia superba: weight specific respiration rate in terms of dry weight $\left(R_{\mathrm{DW}}\right.$, controlled for body size by the scaling exponent 0.9606 ), as a function of temperature; a where $R_{\mathrm{DW}}$ is in the linear domain and temperature is in ${ }^{\circ} \mathrm{C}$, $\mathbf{b}$ where $R_{\mathrm{DW}}$ is in the log domain (LN) and temperature is in ${ }^{\circ} \mathrm{C}$, $\mathrm{c}$ where both $R_{\mathrm{DW}}$ and temperature are

of the two groups was around $300 \mu 1 \mathrm{O}_{2} \mathrm{gDW}^{-0.9606} \mathrm{~h}^{-1}$, with the medians of females and sub-adults both around $800 \mu \mathrm{IO}_{2} \mathrm{gDW}^{-0.9606} \mathrm{~h}^{-1}$, and those of juveniles and males around $1100 \mu \mathrm{lO}_{2} \mathrm{mgDW}^{-0.9606} \mathrm{~h}^{-1}$.

\section{Discussion}

\section{Effect of temperature on respiration rate}

Within the natural temperature range of Antarctic krill $\left(-1.8^{\circ} \mathrm{C}\right.$ to $\left.5.5^{\circ} \mathrm{C}\right)$, a single Arrhenius function was found to describe adequately the relationship between weight-specific respiration rate and temperature. This dataset combined previously published studies with new data obtained by the present study on the stock at South Georgia, where some of
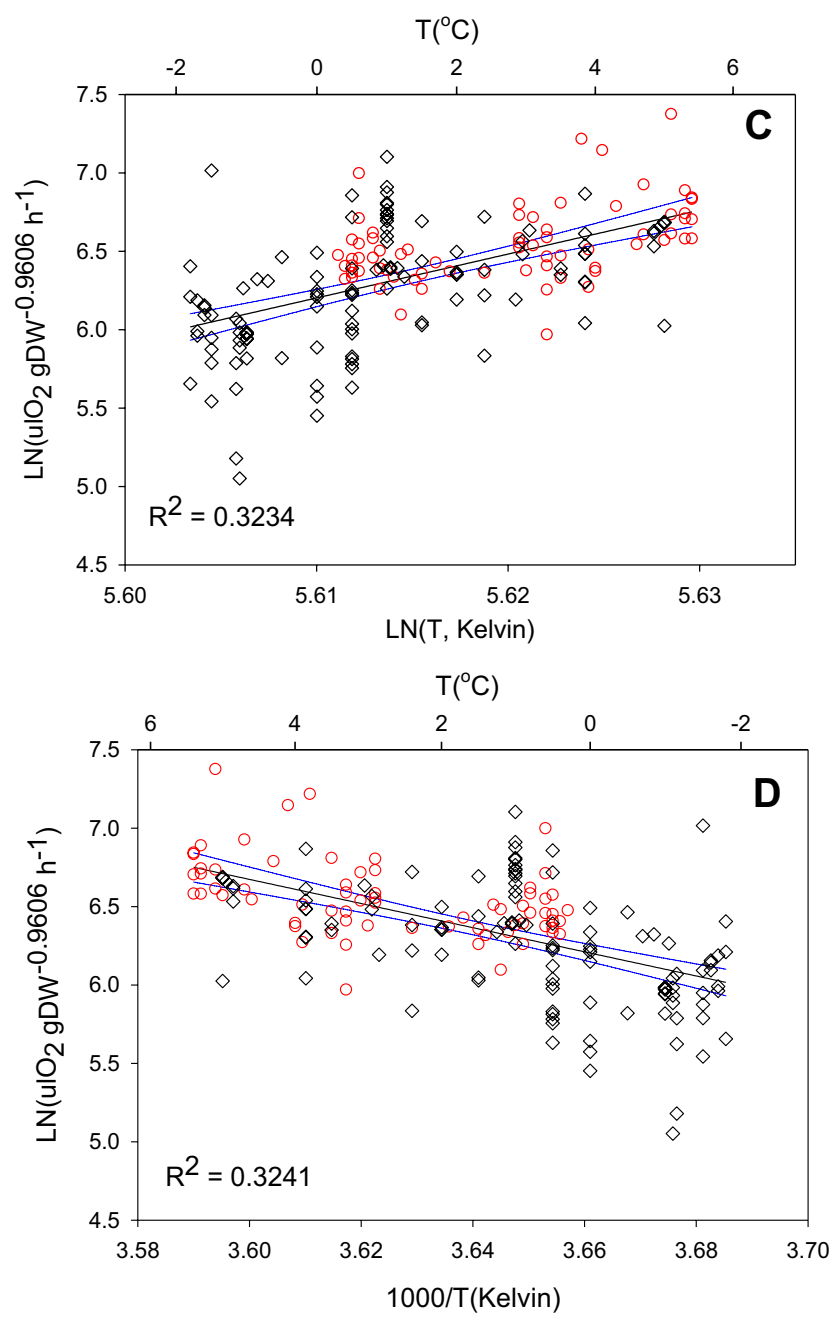

in the log domain (LN), with temperature expressed in Kelvin, $\mathbf{d}$ an Arrhenius plot, where $R_{\mathrm{DW}}$ is in the log domain (LN) and temperature is in inverse Kelvin. a-d are comprised of the AMBIENT dataset, combining data from the present study ( $S G \_$ambient) with previously published data $(C O M P)$. $\mathbf{a}-\mathbf{d}$ are each fitted by a linear regression

the warmest temperatures within the distributional range of Antarctic krill are observed. In adhering to an Arrhenius function, Antarctic krill weight-specific respiration rates were found to increase logarithmically from the coldest to the warmest environments across its distributional range. Applying the van't Hoff's generalisation produced a $Q_{10}$ value of 2.8 , implying that respiration rate in the warmest regions is almost double that in the coldest.

This finding differs from some previously published studies. McWhinnie and Marciniak (1964), Rakusa-Suszczewski and Opalinski (1978) and Segawa et al. (1979) all considered that Antarctic krill showed a degree of metabolic independence between 0 and $2{ }^{\circ} \mathrm{C}$, with there being little detectable change in respiration rate across this temperature range. By contrast, Hirche (1984) found that the relationship between respiration rate and temperature between 0 and $5{ }^{\circ} \mathrm{C}$ fitted an 


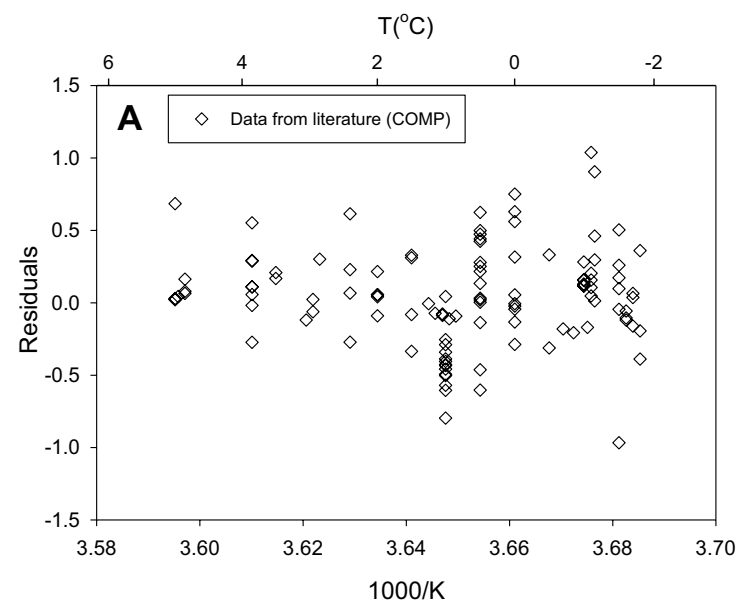

Fig. 7 Euphausia superba: residuals from the fit of the Arrhenius function (Eq. 8) to weight specific respiration rate $\left(R_{\mathrm{DW}}\right)$ data from the AMBIENT dataset. The residuals from the two components of the $A M B I E N T$ dataset (COMP and $\left.S G \_a m b i e n t\right)$ are plotted separately

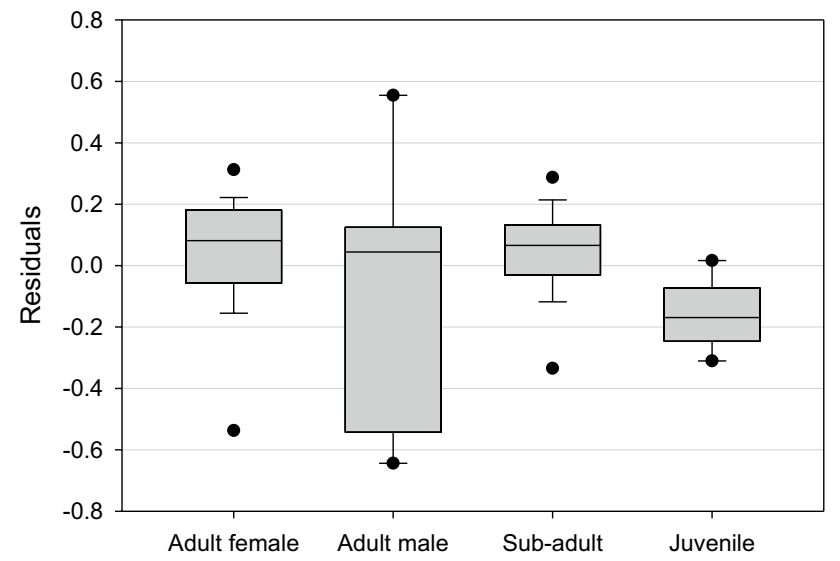

Fig. 8 Euphausia superba: residuals (2nd order) from the fit of quadratic equation (Eq. 9) to residuals of $R_{\mathrm{DW}}$ from the $S G_{-}$ambient dataset, plotted according to sex and developmental stage. The upper and lower limits of the box represent the 25th and 75th percentiles, the line within the box, the median, the upper and lower whiskers, the 10th and 90th percentiles and the dots, the 5th and 95th percentiles

Arrhenius relationship, with a $Q_{10}$ of 2.8. Opalinski (1991) presented an analysis where the $\mathrm{Q}_{10}$ value altered across the temperature range, from 1.22 between $-1.8^{\circ}$ to $2.5^{\circ} \mathrm{C}$, to 1.81 between $2.5^{\circ}$ and $3.5^{\circ} \mathrm{C}$ and then an abrupt rise to 16.5 at temperatures up to $10^{\circ} \mathrm{C}$.

From the polar to the tropical regions, intra-specific $Q_{10}$ values of between 2 and 3 are typical for the respiration rates measured at graded temperatures within the natural ranges of aquatic fishes and crustaceans (Scholander et al. 1953). A $Q_{10}$ value of 2.8 for Antarctic krill, as determined by the present study, places them within this typical range. The present study has the benefit of being able to analyse

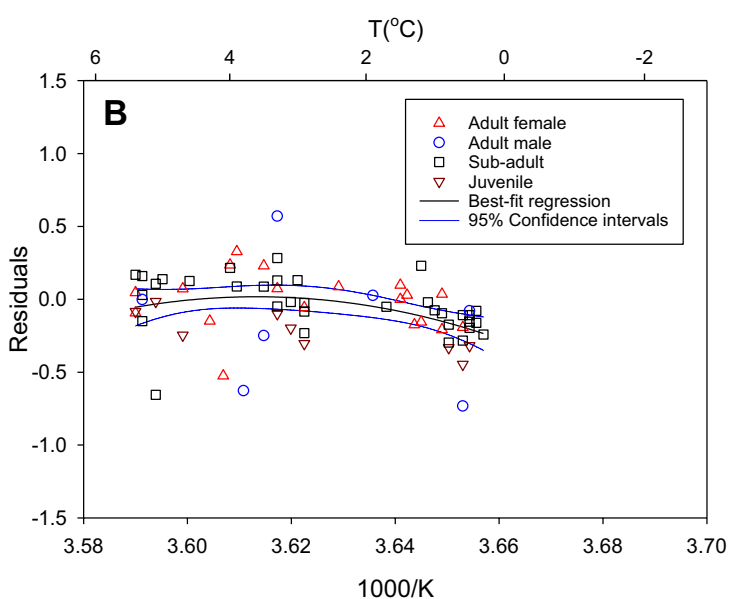

in (a) and (b) respectively. Residuals from the COMP component show no further relationship with temperature. Residuals from the $S G \_a m b i e n t$ component show a further relationship with temperature, best fitted by a quadratic function (Eq. 9)

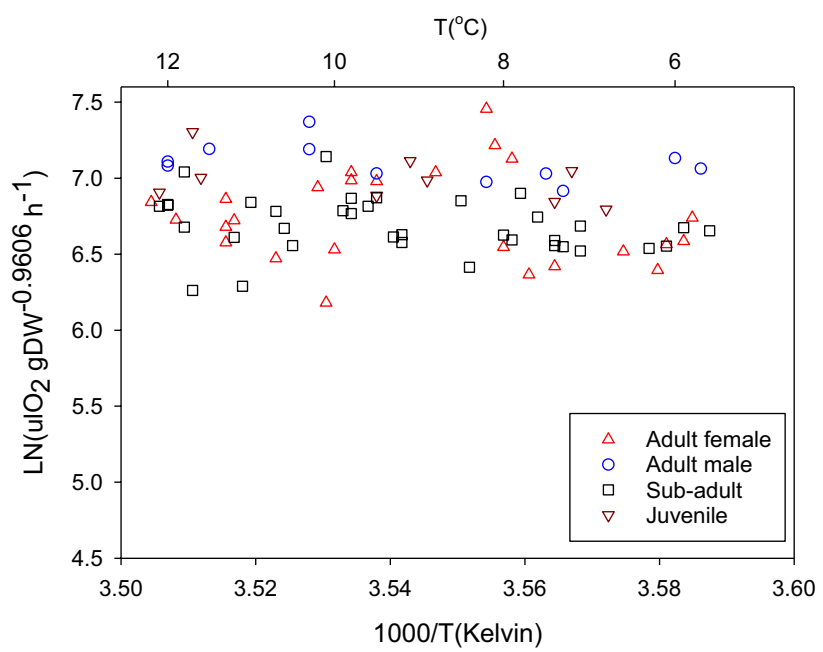

Fig. 9 Euphausia superba: weight-specific respiration rate in terms of dry weight $\left(R_{\mathrm{DW}}\right.$, controlled for body size by the scaling exponent 0.9606 ), as a function of temperature, where minimum incubation temperature is $5.6{ }^{\circ} \mathrm{C}$ and maximum incubation temperature, $12.2{ }^{\circ} \mathrm{C}$ (SG_extreme dataset). No relationship was found between $R_{\mathrm{DW}}$ and temperature within this temperature range

data compiled from a large number of respiration rate studies across a diversity of Southern Ocean environments. It has also been able to add a considerable amount of new data to the warmer part of the distributional range, which has previously been poorly studied in this regard. This more comprehensive data set provides a wider perspective to determine a universal relationship between respiration rate and temperature in Antarctic krill. Nevertheless, as further analysis in the present study shows, there may be regional deviations from this relationship, which could explain the 
differing interpretations in the previous individual studies mentioned above.

\section{Lack of metabolic compensation in Antarctic krill}

The present study did not find any evidence that the stock of Antarctic krill at South Georgia compensated metabolically for the warmer ambient temperatures found there, rather, their respiration rates were higher in accordance with the expectations of an Arrhenius function. Metabolic compensation would otherwise be indicated through either a failure to fit such a function (since the relationship between respiration rate and temperature would not be significantly different from 0 ), or in a significant negative deviation from any such function with increasingly warmer temperatures. Neither of these patterns were found within the natural seasonal temperature range. The present findings for Antarctic krill differ from those of Saborowski et al. (2002) on Northern krill, where metabolic rates were similar between thermally contrasting environments. Saborowski et al. (2002) stated that this pattern was the result of adaptation to local conditions. In an accompanying study, Patarnello et al. (1996) found Northern krill stocks within the three different localities to be genetically distinct, inferring that there had been little exchange of individuals and that populations were relatively isolated from each other. Although a lack of exchange is not a necessary pre-requisite for local adaptation to take place (Sanford and Kelly 2011), it is likely to reinforce any such process (Slatkin 1987).

Whether there are distinct stocks of Antarctic krill in different Southern Ocean regions has yet to be fully resolved from the genetics perspective (Deagle et al. 2015). Although South Georgia is geographically remote from the main population centres of Antarctic krill further south (Atkinson et al. 2008), it has long been postulated that the high biomass of Antarctic krill found there is most likely a result of an influx of stocks from elsewhere (Marr 1962; Mackintosh 1973). Net sample analyses have failed to find evidence of local recruitment at South Georgia given the lack of any early to mid-stage larvae in its surrounding waters (Tarling et al. 2007; Perry et al. 2019). Models have shown that Antarctic krill can arrive at South Georgia in the prevailing flow of the Antarctic Circumpolar Current (ACC, Hofmann et al. 1998; Murphy et al. 1998; Thorpe et al. 2007). Accordingly, variability in the abundance of Antarctic krill at South Georgia has mainly been explained through differences in the amount of krill that becomes entrained within the ACC flow at sites upstream of South Georgia (Murphy et al. 1998; Brierley et al. 1999), or to variability in the transport mechanism itself (Thorpe et al. 2002; Trathan et al. 2003; Reid et al. 2010). The transport and regular mixing of stocks means that the Antarctic krill population at South Georgia is unlikely to be genetically isolated.

\section{Regional acclimation}

We found that the Arrhenius function fitted to all Antarctic krill respiration rate data within the natural environmental temperature range provided an adequate description of the relationship between temperature and respiration rate observed in the South Georgia stock. However, there was an increasing deviation from this function towards the lowest temperatures encountered at South Georgia $\left(0-2{ }^{\circ} \mathrm{C}\right)$. Specifically, as temperatures decreased below $2{ }^{\circ} \mathrm{C}$, respiration rates of South Georgia krill were higher than predicted by the Arrhenius function. Hence, between 0 and $2{ }^{\circ} \mathrm{C}$, South Georgia krill had significantly higher respiration rates than stocks located elsewhere.

It is possible that one source of this deviation is experimental error. In designing the protocol for the present study, the aim was to emulate that of previous respiration rate studies to provide a comparative dataset. Prior to incubation, the krill were maintained for at least $12 \mathrm{~h}$, to complete digestion, but for no more than $48 \mathrm{~h}$, to avoid maintenance effects. Incubations were carried out in closed vessels. In the case of juveniles and sub-adults, multiple individuals were enclosed per vessel to ensure a measurable drop in $\mathrm{O}_{2}$ concentration within the incubation period, which was between 60 and $90 \mathrm{~min}$. With regards prior incubation, Opalinski (1991) found that keeping animals under laboratory conditions for even 2 days exerted no significant effect on the metabolic rate. Analogous findings were reported by McWhinnie and Marciniak (1964), who found that the level of Antarctic krill metabolism remained unchanged over the 6 days postcapture. Opalinski (1991) found that the size of the measuring vessel (100-1000 ml) exerted no effect on Antarctic krill metabolic rate and stated that the results obtained upon using vessels of differing capacity are fully comparable. In terms of $\mathrm{O}_{2}$ saturation within incubation vessels, Kils (1979) reported that Antarctic krill are very sensitive to hypoxia and that metabolic rate reached a maximum at $85 \%$ saturation. However, Opalinski (1991) found no change in metabolic rate between 97 and $85 \%$ saturation, while Clarke and Morris (1983) reported no change in filtration and locomotor activity down to $30 \% \mathrm{O}_{2}$ saturation. With such a high energetic demand to remain pelagic (Kils 1981; Swadling et al. 2005), it is likely that individual Antarctic krill must maintain a relatively constant metabolic rate despite the variable $\mathrm{O}_{2}$ concentrations they may experience, particularly within the body of swarms (Johnson et al. 1984; Brierley and Cox 2010).

If one can exclude the influence of experimental error as an explanatory factor, the significant difference between the respiration rates of South Georgia krill from other stocks 
between 0 and $2{ }^{\circ} \mathrm{C}$ must have some biological cause. In particular, local acclimation may have a role to play. In a study of stocks at the Antarctic Peninsula, McWhinnie and Marciniak (1964) found that animals placed at $4{ }^{\circ} \mathrm{C}$ died within $24 \mathrm{~h}$. Aarset and Torres (1989) also agreed that $4{ }^{\circ} \mathrm{C}$ was the upper lethal temperature for this species. Accordingly, Opalinski (1991) defined the main habitable thermal range for Antarctic krill to be between $-1.8{ }^{\circ} \mathrm{C}$ and $3{ }^{\circ} \mathrm{C}$. The fact that Antarctic krill maintain high levels of biomass at South Georgia, where temperatures reach up to $5.5^{\circ} \mathrm{C}$ (Whitehouse et al. 2008), suggests that such an upper lethal temperature is not universal to all stocks and additional levels of physiological tolerance is possible in some. In a scenario where stocks reach South Georgia during winter, acclimation to warmer temperatures may be built up over the subsequent season as temperatures gradually increase to their late summer maximum. These warm-acclimated stocks may then persist within the South Georgia region for a number of further years, as indicated by regional population dynamic studies (Reid et al. 2010).

Nevertheless, increasing levels of tolerance to warmer temperatures is also likely to incur a metabolic cost. Over seasonal timescales, species adjust their metabolic rates through a number of mechanisms, of which alteration of the density and capacity of mitochondria appears to be particularly key (Pörtner 2002). Through warm acclimation, mitochondrial densities and capacities are decreased in an effort to reduce energetic expenditure on processes such as proton leakage. Such acclimation may allow krill to tolerate warmer temperatures without excessive energetic costs. However, exposing warm-acclimated krill to colder temperatures, particularly on an acute basis, means that these cellular processes have a lower functionality. Costly higher level functions, such as increased ventilation and circulation, may be required for metabolic processes to continue at sufficient rates when exposed to the cold. Comparatively high levels of respiration may therefore be necessary for South Georgia krill to remain viable at colder temperatures and this may represent a trade-off to enable enhanced tolerance of warmer conditions.

\section{Antarctic krill have a high scaling exponent}

This study found that the power function relating respiration rate to body weight for all Antarctic krill data (i.e. previously published and the present study) had a relatively high scaling exponent $(b)$ of 0.9606 . This is in agreement with Opalinski (1991), where an exponent of 0.9 (SD 0.1) was derived from a compilation of 12 studies. By comparison, Ross (1982) obtained values of between 0.7 and 0.8 for Euphausia pacifica raised in the laboratory. Ikeda (2013) derived a value of 0.75 in a compilation of 24 different euphausiid species.
Across the animal kingdom (from Protozoa to large mammals), the general rule is that the power function relationship between respiration rate and body weight has an exponent between 0.6 and 0.8 across all organisms with a mean of 0.75 ( \pm 0.15 , Hemmingsen 1960$)$. The most likely explanation is that body weight includes skeletal, connective and adipose tissue, which has lower metabolic demands than muscular, glandular and nervous tissue whose increase is proportionally smaller in larger organisms. The relatively high exponent derived by the present study indicates that adult Antarctic krill do not experience a net benefit in metabolic costs through increasing in size, implying that becoming larger is metabolically expensive in relative terms. This may be a product of the energetic demands of overcoming negative buoyancy in Antarctic krill (Kils 1981; Swadling et al. 2005), which means that levels of muscular tissue must be maintained relative to overall body weight.

\section{Influence of sex and maturity stage}

The present study found that juveniles had a significantly lower weight-specific respiration rate compared to the more mature stages within the natural environmental temperature range. This finding agrees with that of Klekowski and Opalinski (1989), who also found juvenile weight-specific respiration rate to be lower than that of adults. It indicates that there is a metabolic cost to maturation in this species. Even at the sub-adult stage, females are starting to develop their ovaries and initiating the production of oogonia (CuzinRoudy and Amsler 1991). The continued production and maturation of both male and female gametes over the course of adulthood places further physiological demands, as does the growth of external secondary sexual characteristics, such as the thelycum in females and petasma in males.

More unexpected was the lack of any significant difference between the respective weight-specific respiration rates of sub-adults, adult males and adult females within the natural environmental temperature range. Klekowski et al. (1991) and Rakusa-Suszczewski and Opalinski (1978) also found weight-specific respiration rate of Antarctic krill adults to be independent of sex and maturity stage. The large distended ovaries of females, filled with lipid rich oocytes, implies a lifestyle with a large net energy gain sufficient to resource such a trait. An equivalent level of net energy gain is not required by the males, who are much less energy rich by comparison (Clarke and Morris 1983). The greater net energy gain of the females could be achieved through maintaining a comparatively lower metabolic rate. However, the lack of any significant difference in respiration rates between the sexes, even accounting for different maturity stages within adult females, indicates that this is not the case. Alternatively, it appears that the energetic investment made 
in maturing the ovary must be achieved through greater consumption of resources, probably at some greater risk to the individual (Tarling 2003).

\section{Physiological capacity of Antarctic krill at South Georgia}

$5.5{ }^{\circ} \mathrm{C}$ represents the highest temperatures likely to be encountered in waters around South Georgia. However, it is instructive to consider how individuals cope with even higher temperatures as a means of assessing their aerobic scope (i.e. the capacity to increase aerobic metabolic rate above maintenance levels, or otherwise, the difference between routine and maximum metabolic rate). The present study found no consistent change in respiration rate in temperatures between 5.5 and $12.2{ }^{\circ} \mathrm{C}$ in juvenile, sub-adult or adult stages. Hence, whereas individuals were able to adjust respiration rate according to changes in temperature between 0 and $5.5^{\circ} \mathrm{C}$, there was no capacity adjust respiration rate further beyond $5.5^{\circ} \mathrm{C}$.

At the limit of their aerobic scope, individuals reach a point where oxygen levels in the body fluids start to fall and the capacity to adjust respiration becomes progressively limited (Pörtner 2002). As temperatures increase further, excessive oxygen demand causes insufficient oxygen levels in the body fluids until a high critical threshold temperature is reached. Aerobic scope then disappears and a transition to an anaerobic mode of mitochondrial metabolism occurs, with cellular energy levels becoming progressively insufficient. As a model species for crustaceans, the spider crab, Maja squinado, was found to maintain circulatory oxygen concentrations with rising temperature through increasing heart and ventilation rates to compensate for the rise in oxygen demand (Frederich and Portner 2000). A point was eventually reached (the high pejus temperature threshold) where ventilation and heart rates became more or less constant and independent of temperature, indicating capacity limitation. Circulatory oxygen concentrations then decreased as the continued rise in oxygen demand was no longer compensated for by an increase in ventilation and circulation. Eventually, an upper critical temperature was reached where ventilatory and circulatory activity collapsed.

In Antarctic krill at South Georgia, it appears that the high pejus temperature threshold is reached at $5.5{ }^{\circ} \mathrm{C}$. At this point, it is likely that individuals increasingly revert to anaerobic mitochondrial metabolism. Nevertheless, the continued survival of individuals at $12.2{ }^{\circ} \mathrm{C}$, at least over the 90 min of exposure, indicates that a short term upper critical temperature had not been reached and vital metabolic functions could still be performed. This is consistent with Cascella et al. (2015) who, in performing short-term exposures to acute temperature increases, found E. superba from Terre Adelie to have Critical Temperature maximum of $15.8 \pm 0.1^{\circ} \mathrm{C}$., although the heat shock response of Hsp 70 appeared to be relatively weak compared with temperate species. In Northern krill, Spicer et al. (1999) considered anaerobic metabolism with respect to the ability of individuals to survive in oxygen poor waters and found this physiological capacity to be poorly developed but sufficient to endure such periods. However, high mortality rates were observed if incubation conditions were made even slightly more severe, indicating they were close to their physiological limits at such times. Tolerance of oxygen poor conditions in Antarctic krill may be a necessary adaptation to living within large swarms (Johnson et al. 1984; Brierley and Cox 2010). However, it is likely that anaerobic metabolism can only be utilised for short periods so that the burden of anaerobic metabolites does not become too large (Spicer and Saborowski 2010). The present study shows that sea temperatures above $5.5^{\circ} \mathrm{C}$ would make Antarctic krill revert to anaerobic metabolism, which would be unsustainable over the long term.

\section{Concluding remarks}

The biomass of Antarctic krill at South Georgia is notably variable between, and even within, years (Fielding et al. 2014). Much of this variability is considered to be a product of fluctuations in the success of recruitment events upstream of South Georgia. Murphy et al. (2007), for instance, found a strong correlation between recruitment and time-lagged anomalies in sea surface temperature across the wider Scotia Sea. The present study indicates that, even in the event of a successful wave of recruitment into the South Georgia region, their physiological limitations may mean that local conditions are unsuitable for further persistence in the region. There remain certain behavioural counter-measures of which Antarctic krill are capable, such as vertical migrations into deeper, cooler waters or living within smaller, more dispersed swarms to minimise levels of oxygen stress. However, the efficacy of such behaviours as a means of overcoming increasing water temperatures at South Georgia remains a matter for further research.

Acknowledgements I thank the officers, crew and scientists of the RRS James Clark Ross for their assistance during the research cruise JR245. Particular thanks to Magnus Johnson, Neil Thompson, Natalie Ensor, Gabi Stowasser, Sophie Fielding and Angus Atkinson for their assistance in the deployment of nets and subsequent handling of krill. Thanks also to Peter Enderlein for his technical expertise in the rigging of nets.

Funding The scientific cruise JR245 (Polar Ocean Ecosystem Time Series-Western Core Box) and the time of GAT were funded as part of the Ecosystems Programme at the British Antarctic Survey, Natural Environment Research Council, a part of UK Research and Innovation. 
Data availability Temperature profile and standard body length data are accessible on request to the Polar Data Centre at the British Antarctic Survey (www.bas.ac.uk/data/uk-pdc/). All respiration rate data are provided as part of the Electronic Supplementary Material.

\section{Compliance with ethical standards}

Conflict of interest I declare there were no conflicts of interests in the production of this work.

Ethical approval All work was completed in compliance with British Antarctic Survey (BAS) procedures, following the Antarctic Treaty Environmental Protocol (1996), which requires the prior assessment of all activities in the Antarctic Treaty Area, and is applied by BAS with equal rigour to South Georgia. The present work applies to BAS Environmental Assessment PA Reference Number AFI 9/07 and CGS61. Work on Antarctic krill (Euphausia superba) is exempt from the UK Animals (Scientific Procedures) Act 1986, but all work was compliant with recommended procedures in the handling and treatment of specimens.

Open Access This article is licensed under a Creative Commons Attribution 4.0 International License, which permits use, sharing, adaptation, distribution and reproduction in any medium or format, as long as you give appropriate credit to the original author(s) and the source, provide a link to the Creative Commons licence, and indicate if changes were made. The images or other third party material in this article are included in the article's Creative Commons licence, unless indicated otherwise in a credit line to the material. If material is not included in the article's Creative Commons licence and your intended use is not permitted by statutory regulation or exceeds the permitted use, you will need to obtain permission directly from the copyright holder. To view a copy of this licence, visit http://creativecommons.org/licenses/by/4.0/.

\section{References}

Aarset AV, Torres JJ (1989) Cold resistance and metabolic responses to salinity variations in the amphipod Eusirus antarcticus and the krill Euphausia superba. Polar Biol 9:491-497. https://doi. org/10.1007/Bf00261032

Atkinson A, Whitehouse MJ, Priddle J, Cripps GC, Ward P, Brandon MA (2001) South Georgia, Antarctica: a productive, cold water, pelagic ecosystem. Mar Ecol Prog Ser 216:279-308. https://doi. org/10.3354/meps 216279

Atkinson A, Shreeve RS, Hirst AG, Rothery P, Tarling GA, Pond DW, Korb R, Murphy EJ, Watkins JL (2006) Natural growth rates in Antarctic krill (Euphausia superba): II. Predictive models based on food, temperature, body length, sex, and maturity stage. Limnol Oceanogr 51:973-987. https://doi.org/10.4319/1o.2006.51.2.0973

Atkinson A, Siegel V, Pakhomov EA, Rothery P, Loeb V, Ross RM, Quetin LB, Schmidt K, Fretwell P, Murphy EJ, Tarling GA, Fleming AH (2008) Oceanic circumpolar habitats of Antarctic krill. Mar Ecol Prog Ser 362:1-23. https://doi.org/10.3354/meps07498

Brierley AS, Cox MJ (2010) Shapes of krill swarms and fish schools emerge as aggregation members avoid predators and access oxygen. Curr Biol 20:1758-1762. https://doi.org/10.1016/j. cub.2010.08.041

Brierley AS, Demer DA, Watkins JL, Hewitt RP (1999) Concordance of interannual fluctuations in acoustically estimated densities of Antarctic krill around South Georgia and Elephant Island: biological evidence of same-year teleconnections across the Scotia Sea. Mar Biol 134:675-681. https://doi.org/10.1007/s0022 70050583

Cascella K, Jollivet D, Papot C, Léger N, Corre E, Ravaux J, Clark MS, Toullec J-Y (2015) Diversification, evolution and sub-functionalization of $70 \mathrm{kDa}$ heat-shock proteins in two sister species of antarctic krill: differences in thermal habitats, responses and implications under climate change. PLoS ONE. https://doi.org/10.1371/ journal.pone. 0121642

Clarke A, Morris DJ (1983) Towards an energy budget for krill: the physiology and biochemistry of Euphausia superba Dana. Polar Biol 2:69-86. https://doi.org/10.1007/Bf00303172

Croxall J, McCann T, Prince P, Rothery P (1988) Reproductive performance of seabirds and seals at South Georgia and Signy Island, South Orkney Islands, 1976-1987: implications for Southern Ocean monitoring studies. In: Sahrhage D (ed) Antarctic Ocean and resources variability. Springer-Verlag, Berlin, pp 261-285

Croxall J, Reid K, Prince P (1999) Diet, provisioning and productivity responses of marine predators to differences in availability of Antarctic krill. Mar Ecol Prog Ser 177:115-131. https://doi. org/10.3354/meps177115

Cuzin-Roudy J, Amsler MO (1991) Ovarian development and sexual maturity staging in Antarctic Krill, Euphausia superba Dana (Euphausiacea). J Crustac Biol 11:236-249. https://doi. org/10.2307/1548361

Cuzin-Roudy J, Irisson J, Penot F, Kawaguchi S, Vallet C (2014) Southern Ocean Euphausiids. In: De Broyer C, Koubbi P (eds) Biogeographic Atlas of the Southern Ocean. The Scientific Committee on Antarctic Research, Cambridge, pp 309-320

Deagle BE, Faux C, Kawaguchi S, Meyer B, Jarman SN (2015) Antarctic krill population genomics: apparent panmixia, but genome complexity and large population size muddy the water. Mol Ecol 24:4943-4959. https://doi.org/10.1111/mec.13370

Everson I (1984) Marine interactions. In: Laws R (ed) Antarctic ecology. Academic Press, London, pp 781-783

Everson I, Goss C (1991) Krill fishing activity in the southwest Atlantic. Antarct Sci 3:351-358. https://doi.org/10.1017/S095410209 1000445

Fielding S, Watkins JL, Trathan PN, Enderlein P, Waluda CM, Stowasser G, Tarling GA, Murphy EJ (2014) Interannual variability in Antarctic krill (Euphausia superba) density at South Georgia, Southern Ocean: 1997-2013. Ices J Mar Sci 71:2578-2588. https ://doi.org/10.1093/icesjms/fsu104

Flores H, Atkinson A, Kawaguchi S, Krafft BA, Milinevsky G, Nicol S, Reiss C, Tarling GA, Werner R, Rebolledo EB, Cirelli V, CuzinRoudy J, Fielding S, Groeneveld JJ, Haraldsson M, Lombana A, Marschoff E, Meyer B, Pakhomov EA, Rombola E, Schmidt K, Siegel V, Teschke M, Tonkes H, Toullec JY, Trathan PN, Tremblay N, Van de Putte AP, van Franeker JA, Werner T (2012) Impact of climate change on Antarctic krill. Mar Ecol Prog Ser 458:1-19. https://doi.org/10.3354/meps09831

Frederich M, Portner HO (2000) Oxygen limitation of thermal tolerance defined by cardiac and ventilatory performance in spider crab, Maja squinado. Am J Physiol Regul Integr Comp Physiol 279:R1531-R1538

Gille ST (1950s) Warming of the Southern Ocean since the 1950s. Scienc 295:1275-1277. https://doi.org/10.1126/science.1065863

Hemmingsen AM (1960) Energy metabolism as related to body size and respiratory surface, and its evolution. J Rep Steno Meml Hosp 13:1-110

Hirche HJ (1984) Temperature and metabolism of plankton.1. Respiration of Antarctic zooplankton at different temperatures with a comparison of Antarctic and Nordic Krill. Comp Biochem Phys A 77:361-368. https://doi.org/10.1016/0300-9629(84)90074-4 
Hofmann EE, Klinck JM, Locarnini RA, Fach B, Murphy E (1998) Krill transport in the Scotia Sea and environs. Antarc Sci 10:406415. https://doi.org/10.1017/S0954102098000492

Ikeda T (1984) Sequences in metabolic rates and elemental composition $(\mathrm{C}, \mathrm{N}, \mathrm{P})$ during the development of Euphausia superba Dana and estimated food requirements during its life-span. J Crustac Biol 4:273-284. https://doi.org/10.1163/1937240x84x00651

Ikeda T (2013) Respiration and ammonia excretion of euphausiid crustaceans: synthesis toward a global-bathymetric model. Mar Biol 160:251-262. https://doi.org/10.1007/s00227-012-2150-z

Johnson MA, Macaulay MC, Biggs DC (1984) Respiration and excretion within a mass aggregation of Euphausia superba-implications for krill distribution. J Crustac Biol 4:174-184. https://doi. org/10.1163/1937240x84x00570

Kils U (1979) Swimming speed and escape capacity of Antarctic krill, Euphausia superba. Meeresforschung 27:264-266

Kils U (1981) Swimming behaviour, swimming performance and energy balance of Antarctic krill Euphausia superba. BIOMASS Sci Ser 3:1-121

Klekowski RZ, Opalinski KW (1989) Respiratory metabolism of Euphausia superba: oxygen consumption and body weight. In: Proceedings of 21st EMBS, Ossolineum Institute, Wroclaw, pp 109-117

Klekowski RZ, Opalinski KW, Maklygin LG (1991) Respiratory metabolism of Euphausia superba:the effect of gonadal development. In: Klekowski RZ, Opalinski KW (eds) The First Polish-Soviet Antarctic Symposium, pp 109-117

Longhurst A (1998) Ecological geography of the sea. Academic Press, London

Mackintosh NA (1973) Distribution of post-larval krill in the Antarctic. Discov Rep 36:95-156

Makarov RR, Denys CJ (1980) Stages of sexual maturity of Euphausia superba. Scientific Committee for Antarctic Research, Cambridge

Marr JWS (1962) The natural history and geography of the Antarctic krill. Discov Rep 32:33-464

Mauchline J (1980) The biology of mysids and euphausiids. Adv Mar Biol 18:1-681

McWhinnie MA, Marciniak P (1964) Temperature responses and tissue respiration in Antarctic Crustacea with particular reference to the krill Euphausia superba. Biology of the Antarctic Sea. In: Lee MO (ed) Antarct Res Ser, vol 1. American Geophysical Union, Washington, pp 63-72

Meyer B (2012) The overwintering of Antarctic krill, Euphausia superba, from an ecophysiological perspective. Polar Biol 35:15-37. https:// doi.org/10.1007/s00300-011-1120-0

Morris DJ, Watkins JL, Ricketts C, Buchholz F, Priddle J (1988) An assessment of the merits of length and weight measurements of Antarctic krill Euphausia superba. Br Antarct Surv Bull 79:27-50

Murphy EJ, Watkins JL, Reid K, Trathan PN, Everson I, Croxall JP, Priddle J, Brandon MA, Brierley AS, Hofmann E (1998) Interannual variability of the South Georgia marine ecosystem: biological and physical sources of variation in the abundance of krill. Fish Oceanogr 7:381-390. https://doi.org/10.1046/j.1365-2419.1998.00081.x

Murphy EJ, Trathan PN, Watkins JL, Reid K, Meredith MP, Forcada J, Thorpe SE, Johnston NM, Rothery P (2007) Climatically driven fluctuations in Southern Ocean ecosystems. P R Soc B Biol Sci 274:3057-3067. https://doi.org/10.1098/rspb.2007.1180

Nicol S, Foster J, Kawaguchi S (2012) The fishery for Antarctic krillrecent developments. Fish Fish 13:30-40. https://doi.org/10.111 1/j.1467-2979.2011.00406.x

Opalinski K (1991) Respiratory metabolism and metabolic adaptations of Antarctic krill Euphausia superba. J Pol Arch Hydrobiol 38:183-263

Patarnello T, Bargelloni L, Varotto V, Battaglia B (1996) Krill evolution and the Antarctic ocean currents: evidence of vicariant speciation as inferred by molecular data. Mar Biol 126:603-608. https://doi. org/10.1007/Bf00351327

Perry FA, Atkinson A, Sailley SF, Tarling GA, Hill SL, Lucas CH, Mayor DJ (2019) Habitat partitioning in Antarctic krill: spawning hotspots and nursery areas. PLoS ONE. https://doi.org/10.1371/ journal.pone. 0219325

Pörtner HO (2002) Climate variations and the physiological basis of temperature dependent biogeography: systemic to molecular hierarchy of thermal tolerance in animals. Comp Biochem Phys A 132:739761. https://doi.org/10.1016/S1095-6433(02)00045-4

Rakusa-Suszczewski S, Opalinski KW (1978) Oxygen consumption in Euphausia superba. Polsk Arch Hydrobiol 25:633-641

Reid K, Watkins JL, Murphy EJ, Trathan PN, Fielding S, Enderlein P (2010) Krill population dynamics at South Georgia: implications for ecosystem-based fisheries management. Mar Ecol Prog Ser 399:243-252. https://doi.org/10.3354/meps08356

Ross RM (1982) Energetics of Euphausia pacifica I. Effects of body carbon and nitrogen and temperature on measured and predicted production. Mar Biol 68:1-13

Saborowski R, Brohl S, Tarling GA, Buchholz F (2002) Metabolic properties of Northern krill, Meganyctiphanes norvegica, from different climatic zones. I. Respiration and excretion. Mar Biol 140:547-556. https://doi.org/10.1007/s00227-001-0730-4

Sanford E, Kelly MW (2011) Local adaptation in marine invertebrates. Annu Rev Mar Sci 3:509-535. https://doi.org/10.1146/annurevmarine-120709-142756

Schmidt-Nielsen K, Knut S-N (1984) Scaling: why is animal size so important?. Cambridge University Press, Polar

Scholander PF, Flagg W, Walters V, Irving L (1953) Climatic adaptation in arctic and tropical poikilotherms. Physiol Zool 26:67-92

Segawa S, Kato M, Murano M (1979) Oxygen consumption of the Antarctic krill. J Trans Tokyo Univ Fish 3:113-119

Slatkin M (1987) Gene flow and the geographic structure of natural populations. Science 236:787-792. https://doi.org/10.1126/scien ce. 3576198

Spicer JI, Saborowski R (2010) Physiology and metabolism of Northern Krill (Meganyctiphanes norvegica Sars). In: Tarling GA (ed) Advance marine biology. Elsevier Academic Press Inc, San Diego, pp 91-126

Spicer JI, Thomasson MA, Stromberg JO (1999) Possessing a poor anaerobic capacity does not prevent the diet vertical migration of Nordic krill Meganyctiahanes norvegica into hypoxic waters. Mar Ecol Prog Ser 185:181-187. https://doi.org/10.3354/meps185181

Swadling KM, Ritz DA, Nicol S, Osborn JE, Gurney LJ (2005) Respiration rate and cost of swimming for Antarctic krill, Euphausia superba, in large groups in the laboratory. Mar Biol 146:1169-1175

Tarling GA (2003) Sex-dependent diel vertical migration in northern krill Meganyctiphanes norvegica and its consequences for population dynamics. Mar Ecol Prog Ser 260:173-188. https://doi.org/10.3354/ meps 260173

Tarling GA, Cuzin-Roudy J, Thorpe SE, Shreeve RS, Ward P, Murphy EJ (2007) Recruitment of Antarctic krill Euphausia superba in the South Georgia region: adult fecundity and the fate of larvae. Mar Ecol Prog Ser 331:161-179. https://doi.org/10.3354/meps331161

Tarling GA, Ensor NS, Fregin T, Goodall-Copestake WP, Fretwell P (2010) An introduction to the biology of Northern krill (Meganyctiphanes norvegica Sars). In: Tarling GA (ed) Advance marine biology. Elsevier Academic Press Inc, San Diego, pp 1-40

Thorpe SE, Heywood KJ, Brandon MA, Stevens DP (2002) Variability of the southern antarctic circumpolar current front north of South Georgia. J Mar Syst 37:87-105. https://doi.org/10.1016/S0924 -7963(02)00197-5

Thorpe SE, Murphy EJ, Watkins JL (2007) Circumpolar connections between Antarctic krill (Euphausia superba Dana) populations: investigating the roles of ocean and sea ice transport. Deep-Sea Res Pt I 54:792-810. https://doi.org/10.1016/j.dsr.2007.01.008 
Thorpe SE, Tarling GA, Murphy EJ (2019) Circumpolar patterns in Antarctic krill larval recruitment: an environmentally driven model. Mar Ecol Prog Ser 613:77-96. https://doi.org/10.3354/meps12887

Trathan PN, Brierley AS, Brandon MA, Bone DG, Goss C, Grant SA, Murphy EJ, Watkins JL (2003) Oceanographic variability and changes in Antarctic krill (Euphausia superba) abundance at South Georgia. Fish Oceanogr 12:569-583. https://doi.org/10.104 6/j.1365-2419.2003.00268.x

Tremblay N, Werner T, Huenerlage K, Buchholz F, Abele D, Meyer B, Brey T (2014) Euphausiid respiration model revamped: latitudinal and seasonal shaping effects on krill respiration rates. Ecol Model 291:233-241. https://doi.org/10.1016/j.ecolmodel.2014.07.031
Veit RR, Silverman ED, Everson I (1993) Aggregation patterns of pelagic predators and their principal prey, Antarctic Krill, near South Georgia. J Anim Ecol 62:551-564. https://doi.org/10.2307/5204

Whitehouse MJ, Meredith MP, Rothery P, Atkinson A, Ward P, Korb RE (2008) Rapid warming of the ocean around South Georgia, Southern Ocean, during the 20th century: forcings, characteristics and implications for lower trophic levels. Deep-Sea Res Pt I 55:1218-1228. https://doi.org/10.1016/j.dsr.2008.06.002

Publisher's Note Springer Nature remains neutral with regard to jurisdictional claims in published maps and institutional affiliations. 